\title{
Assessment of Psychological Distress among Parents of Children with Cancer
}

\author{
Jihene Feki, Fatma Baklouti, Afef Khanfir \\ Medical Oncology Department Habib Bourguiba Hospital University of Sfax, Sfax, Tunisia \\ Email: fatmabaklouti1@gmail.com
}

How to cite this paper: Feki, J., Baklouti, F. and Khanfir, A. (2021) Assessment of Psychological Distress among Parents of Children with Cancer. Open Journal of Psychiatry, 11, 229-247.

https://doi.org/10.4236/ojpsych.2021.11401 9

Received: June 7, 2021

Accepted: September 14, 2021

Published: September 17, 2021

Copyright $\odot 2021$ by author(s) and Scientific Research Publishing Inc. This work is licensed under the Creative Commons Attribution International License (CC BY 4.0).

http://creativecommons.org/licenses/by/4.0/

\begin{abstract}
Background and Aims: The diagnosis of pediatric cancer is a potentially traumatic event and a major source of psychological distress for parents. The aim of our study was to determine the prevalence and the risk factors of psychological distress among parents of children diagnosed with cancer. Methods: This is a descriptive study carried out on parents of children diagnosed with cancer and treated in the department of medical oncology at the Habib Bourguiba Hospital in Tunisia. Over a period of four months, from the beginning of December 2020 until the end of March 2021, forty-three parents (34 mothers and 9 fathers) were assessed, using psychometric scales of anxiety, depression and post-traumatic stress according to respectively to the Hamilton anxiety rating scale (HAM), the Beck Depression Inventory (BDI) and the Impact of Event Scale (IES-R). Results: Sixteen percent of the parents had scores indicating acute stress and $21 \%$ had scores indicating post-traumatic stress. Eighty six percent of the parents had mild to severe depression and 95\% had minor to major anxiety. Post-traumatic stress and anxiety are significantly correlated with the female sex of parents. Significant correlations are also found between post-traumatic stress scores and symptoms of depression and anxiety. However, our study did not show a significant correlation between the others factors studied and the parents' psychological distress. Conclusion: The prevalence of anxiety and depressive disorders was high among parents of children diagnosed with cancer and a significant correlation was found between stress and anxiety with the female sex of parents. Our results were similar to several studies although other risk factors for psychological distress in parents of children with cancer were described in the literature.
\end{abstract}

\section{Keywords}

Pediatric Cancer, Parents, Anxiety, Depression, Post Traumatic Stress 


\section{Introduction}

Childhood cancer is relatively rare and accounts for only 1 to $3 \%$ of cancers in children under the age of 15 [1].

It is the second leading cause of death for children above the age of 3 years, after a mortal accident [2].

Significant biomedical advances over the past several decades have increased the survival rate for children with cancer to over 70\% (SEER 2007).

However, improved prognosis and survival require prolonged, complicated, and intensive treatment protocols specially the chemotherapy and also radiotherapy, surgery and bone marrow transplantation. These procedures and the many side effects of treatment, impact quality of life not only for the child with cancer, but also for the whole family [3].

When a child is diagnosed with cancer a process known as psychological stress starts which interferes with the family daily's life for a long period of time [4].

The family adaptation to this diagnosis, its treatment and its prognosis has been the focus of some scientific research in the last years [3].

In addition, the data in the literature in terms of the mental health of parents of children with cancer is contradictory and inconclusive. Some studies report the absence of risk of additional psychological damage [5]. However, the majority of studies report worsening symptoms of anxiety, depression, and post-traumatic stress disorder compared to the general population [6]. These studies also identified several risk factors for the development of psychological disorders in parents of children with cancer.

Moreover, this subject remains little studied in our Tunisian context. This is why we deemed it appropriate to carry out this study to describe the prevalence and type of psychological problems faced by parents of children recently diagnosed with cancer and to identify the risk factors inducing these disorders among these parents.

\section{Ethical Authorization}

The verbal and informed consent of the parents was obtained before the questionnaire and after a detailed clarification of the objectives of the study and its conduct.

\section{Patients and Methods}

\subsection{Patients}

This is a descriptive study carried out on parents of children diagnosed with cancer in the department of medical oncology at the Habib Bourguiba Hospital in Tunisia over a period of four months, from the beginning of December 2020 until the end of March 2021. Given the absence of studies addressing this subject in Tunisia, we conducted this preliminary study that we will be the basis for a further study of a larger sample by estimating the number of subjects required. 
We interrogate the parents of children aged less than 18 years old who are undergoing curative or palliative treatment and we excluded the parents of children who refused to be part of the study.

\subsection{Methods}

The parents were interviewed during the hospitalization of their children.

We have collected primary the data about sociodemographic status of the parents and the clinical information about the child in particular the age, the gender, the date of diagnosis, the type of cancer, clinical and histological stage and the treatment options and secondary we have carried a psychometric assessment using various tools:

\section{- The Impact of Event Scale-Revised (IES-R):}

IES- $\mathrm{R}$ is the most widely used instrument for the assessment of post-traumatic stress disorder (PTSD) and acute stress disorder (ASD). [5] The authors currently choose to take a total score above 22 less than one month after the event as being in favor of significant symptoms of acute stress and a score above 36 more than one month after the event as suggesting the presence of post-traumatic stress disorder.

\section{- The Beck Depression Inventory (BDI):}

$\mathrm{BDI}$ is designed to assess the subjective aspects of depression: it is a subjective measure of depression, initially consisting of 21 items, the form of which was reduced by the original author to 13 items. The inventory measures depressive thinking's by providing, for each item, a series of four statements representing increasing degrees of symptoms. For each item, the score ranges from zero to three. The higher the global score, the more depressed the subject is (0 to 39). It alerts the clinician, who uses the different severity levels, to the diagnosis of depression from a score of four and to judge the intensity of this depression:

- 0 to 3: no depression.

- 4 to 7: minor depression.

- 8 to 15: moderate to severe depression.

- 16 and over: severe depression.

\section{- The Hamilton anxiety rating scale (HAM):}

Is one of the first rating scales developed to measure the severity of anxiety symptoms. The scale consists of 14 items, each defined by a series of symptoms, and measures both psychic anxiety (mental agitation and psychological distress) and somatic anxiety (physical complaints related to anxiety). Although the HAM-A remains widely used as an outcome measure in clinical trials, it has been criticized for its sometimes poor ability to discriminate between anxiolytic and antidepressant effects, and somatic anxiety versus somatic side effects. Despite this, the reported levels of inter-rater reliability for the scale appear to be acceptable [6].

\subsection{Statistical Assessment}

Data input and statistical treatment was done with SPSS software Version 20. To 
identify the relationship between the sociodemographic and clinical characteristics of the parents and the psychological disorder we have used the correlation test which concludes the significance when the $\mathrm{p}$ is $<0.05$.

\section{Results}

This is a descriptive trial carried out on 43 parents of children with cancer undergoing treatment at the medical oncological department of the Habib Bourguiba Hospital in Tunisia over a period of four months.

\subsection{Characteristics of the Study Population}

Table 1 illustrates the socio-demographic characteristics of the study population (age, sex, and marital status, and geographic origin, level of scholarity, professional activity, and number of children).

As for the clinical characteristics of the study population and their children, Table 2 illustrates their different features.

\subsection{The Psychiatric Assessment}

According to the IESR-R score, $37 \%$ of the parents had scores in favor of significant symptoms of post-traumatic stress disorder. Sixteen percent of the parents assessed before one month had acute stress and $21 \%$ of the parents assessed after one month had post-traumatic stress. The majority of parents have scores not suggestive of post-traumatic stress disorder (63\%).

Then, according to the BDI depression score, $87 \%$ of the parents had minor to severe depression of which: $34 \%$ had minor depression, $46 \%$ had moderate depression and $7 \%$ of the parents had severe depression only $14 \%$ had a BDI score that did not suggest depression.

For the psychiatric assessment of anxiety, it was according to the Hamilton test and it showed minor anxiety in 34\% of the parents and major anxiety in $61 \%$ of the parents. Only $5 \%$ of the parents had scores that did not suggest anxiety.

Table 3 illustrates the psychiatric assessment using different scores.

Table 1. Socio-demographic characteristics of the study population.

\begin{tabular}{ll}
\hline Age & Extremes: 18 - 68 years; Average age: 37 years \\
Sex & Female: $79.5 \%$; Male: $20.5 \%$ \\
Marital status & Married: $98 \%$; Divorced: $2 \%$ \\
Geographic origin & Urban: $57 \%$; Rural: $43 \%$ \\
Level of schooling & Analphabet: $9 \%$; Schooled: $91 \%$ \\
Professional activity & Regular activity: $23 \%$; Irregular activity: $4 \%$; Unemployed: $73 \%$ \\
Number of children & $<3$ children: $89 \% ;>3$ children: $11 \%$ \\
Monthly income & $<500$ dinars: $22 \% ;>500$ dinars: $78 \%$ \\
Previous Traumatic events & $25 \%$ of the population \\
Family history of cancer & $14 \%$ of the population \\
\hline
\end{tabular}


Table 2. The clinical characteristics of the study population and their children.

\begin{tabular}{ll}
\hline & $<4$ years: $48 \%$ \\
& $4-8$ years: $25 \%$ \\
Age of children with cancer & $8-12$ years: $11 \%$ \\
& $>12$ years: $16 \%$ \\
\hline Sex of children with cancer & Female: $57 \%$ \\
& Male: $43 \%$ \\
\hline Neuroblastoma: 9 children \\
Meduloblastoma: 7 children \\
Nephroblastoma: 5 children \\
Ewing sarcoma: 5 children \\
Osteosarcoma: 2 child \\
Rabdomyosarcoma: 2 child \\
Hepatoblastoma: 1 child \\
Pinealoblastoma: 1 child \\
Cerebral PNET: 1 child \\
Germinal tumor: 1 child \\
\hline Localized: $54.5 \%$ \\
Disseminated: $45.5 \%$ \\
\hline
\end{tabular}

Table 3. Psychiatric assessment.

\begin{tabular}{ll}
\hline $\begin{array}{l}\text {-the time between the announcement of the } \\
\text { diagnosis and the psychiatric assessment }\end{array}$ & $<1$ month: $32 \%$ \\
& $>1$ month: $68 \%$ \\
-the stress assessment & No stress: $63 \%$ \\
& Acute stress: $16 \%$ \\
& Post-traumatic stress : $21 \%$ \\
\hline & No depression: $14 \%$ \\
-the depression assessment & Minor depression: $34 \%$ \\
& Moderate depression: $46 \%$ \\
& Severe depression: $7 \%$ \\
\hline & No anxiety: $5 \%$ \\
The anxiety assessment & Minor anxiety: $34 \%$ \\
& Major anxiety: $61 \%$ \\
\hline
\end{tabular}

\subsection{Correlation between Psychiatric Assessment and Clinical and the Sociodemographic Parameters Used in the Study}

The analysis of the different socio-demographic and clinical factors that could be predictive of the occurrence of post-traumatic stress disorder in parents of children with cancer showed that only the female gender was a risk factor ( $p=0.045$ $<0.05)$. However, there was no significant relationship between the other factors and the occurrence of post-traumatic stress disorder.

Using the correlation test, our study did not show a significant association 
between the different parameters investigated and the occurrence of depression.

Among the socio-demographic parameters studied, only female gender was significantly correlated with anxiety levels in our parents $(\mathrm{p}=0.006<0.05)$.

Significant correlations were also found between post-traumatic stress scores and symptoms of depression and anxiety $(\mathrm{p}=0.04$ and $\mathrm{p}=0.003<0.05)$.

Table 4 detailed the correlation between psychiatric assessment and some sociodemographic and clinical factors.

\section{Discussion}

Pediatric cancers are rare and heterogeneous diseases representing $1 \%$ to $3 \%$ of cancers. They are characterized by the heterogeneity of their primary site and histological type. The major progress in cure rates, from 25\% before 1970 to more than $75 \%$ currently in developed countries, is the result of therapeutic advances, and the development of multi-center clinical trials [7].

In Tunisia, the incidence of childhood cancer is estimated at 400 new cases per year, i.e. 18/100,000 children under 15 years of age according to World Health Organization statistics [8].

The most common types of pediatric cancer are leukemia, brain cancers, lymphomas and solid tumors such as neuroblastoma and Wilms' tumor [9].

In our study, the neuroblastoma is described as the most common tumor (28\%) followed by nephroblastoma, which represent $22 \%$ of cases and after that follow the diagnostic of meduloblastoma and Ewing sarcoma each of which represents $16 \%$ of cases.

When parents are confronted with the diagnostic of cancer in their child, a process starts, involving the appraisal of the stressor, followed by strain, and stress reactions, or the manifestations of strain, which become manifest as uncertainty, anxiety, depressive symptoms, and PTSS.

These feelings are, especially identified at critical moments (initial diagnosis, treatment, but also relapses) [10].

Learning that one's child has a life-threatening disease is a qualifying event for PTSD or PTSS [11]. Approximately $68 \%$ of mothers and $57 \%$ of fathers of children currently in treatment report PTSS in the moderate to severe range [12].

Table 4. Correlation between psychiatric assessment and some sociodemographic and clinical factors.

\begin{tabular}{cccc}
\hline & Post-traumatic stress disorder & anxiety & Depression \\
\hline Sex & $\mathrm{P}=0.045$ & $\mathrm{P}=0.006$ & $\mathrm{P}=0.76$ \\
Age of parents & $\mathrm{P}=0.92$ & $\mathrm{P}=0.065$ & $\mathrm{P}=0.53$ \\
Level of schooling & $\mathrm{P}=0.18$ & $\mathrm{P}=0.45$ & $\mathrm{P}=0.41$ \\
Professional activity & $\mathrm{P}=0.93$ & $\mathrm{P}=0.41$ & $\mathrm{P}=0.57$ \\
Monthly income & $\mathrm{P}=0.31$ & $\mathrm{P}=0.62$ & $\mathrm{P}=0.62$ \\
Previous traumatic event & $\mathrm{P}=0.96$ & $\mathrm{P}=0.4$ & $\mathrm{P}=0.12$ \\
Cancer stage & $\mathrm{P}=0.71$ & $\mathrm{P}=0.1$ & $\mathrm{P}=0.71$ \\
\hline
\end{tabular}


In our study, only $16 \%$ of parents report a PTSS.

Sub-clinical PTSS such as intrusive thoughts about cancer, physiological arousal at reminders, and avoidance of treatment-related events have been found to be even more prominent [13].

Acute stress disorders occur in the first month after the trauma event. Their criteria are based on intrusive symptoms (such as involuntary rememorize of the traumatic event, also known as reliving), negative mood, dissociative symptoms (such as second state) the avoidance and waking disorders (ranging from sleep disruption to hyper vigilance).

These disorders are often associated with concentration difficulties.

In the case of post-traumatic stress disorder, there are also cognitive alterations (such as forgetting of the features of the trauma) [14].

In our study, a $21 \%$ report a PTSD.

Table 5 illustrates the prevalence of stress in parents of children with cancer in the comparison with the results of the literature.

In our trial, the prevalence of acute stress is relatively high, about $37 \%$ of the parents ( $2 \%$ of the fathers against $35 \%$ of the mothers).

This prevalence of acute stress significantly exceeds that of parents of injured children, which is still the leading cause of pediatric mortality which does not exceed $25 \%$ [18].

This is due to the parents' perception of cancer as a source of childhood suffering, pain (disease, treatment, medical procedures) and its high associations with death [19].

In our study, $21 \%$ of the parents assessed after one month of diagnosis had scores in favor of post-traumatic stress. These findings are comparable to those cited in the literature, particularly those of Dunn et al. [20] and McCarthy [17].

These results may be attributed also to the fact that the parents in our study were predominantly represented by mothers and, following the results of the literature, the prevalence of post-traumatic stress symptoms in mothers is 2.49 times higher than in fathers [15].

It is considered that the chronicity of the disease, both in term of treatment and possible relapse is probably the most important stressor [21].

The therapeutic procedure for the acute stress include the Cognitive-behavioral therapy, which is particularly efficient in the treatment of acute stress and the antidepressants, including selective serotonin reuptake inhibitors, which are sometimes prescribed to reduce the severity of PTSD symptoms.

Table 5. Prevalence of stress in parents of children with cancer in the literature.

\begin{tabular}{ccccc}
\hline Authors & country & Year & Size of sample & Prevalence of stress \\
\hline Our study & Tunisia & 2021 & 43 & $37 \%$ \\
Iranmanesh [16] & Iran & & 200 & $75 \%$ \\
Kazak [17] & USA & 2008 & 249 & $65 \%$ \\
McCarthy [18] & Australia & 2012 & 145 & Fathers $60 \%$ \\
& & & & Mathers $61 \%$ \\
\hline
\end{tabular}


Parents may show depressive symptoms in reaction to their child's cancer diagnosis.

These symptoms may include: a depressed mood; persistent sorrow, anxiety or emptiness, feelings of hopelessness or pessimism, feelings of guilt or helplessness, tiredness or low energy, significant decrease in interest or pleasure, difficulty in concentration or in making decisions, agitation, insomnia or hypersomnia [14].

Our study showed a high prevalence of depression in parents of children with cancer. About $86 \%$ of our parents had mild to severe depression (67\% of mothers and $19 \%$ of fathers). Our results indicate that about $7 \%$ of the parents had scores in favor of severe depression and $46 \%$ had scores in favor of moderate depression. These findings are similar to the results of previous studies including that of SK Al-Maliki in Iraq which found an estimated prevalence of $70.5 \%$ (77.2\% among fathers and 57.1\% among mothers) [22] and Battcharya $\mathrm{K}$ in India which found a prevalence of depression about 78.3\% [23].

This prevalence was lower in the study by K. Dietrich in Germany, which found significant depression scores in about $42 \%$ of the parents [24]. These results were similar to those of Kostak's study in Turkey which found depressive symptoms in about half of the mothers and one third of the fathers [25]. This difference may be due to the difference in the assessment tools employed and the delay after the announcement of the diagnosis [7].

Table 6 detailled the comparison between our results and the findings in the literature in terms of depression in parents of children with cancer.

The announcement of a child's cancer is a difficult moment. The family lived in a world of confusion and anxiety where all the members take care obsessively with their unique child in order to heal his suffering and thus to decrease their distress and anxiety.

In our study, we found a significant increase in anxiety among parents of children with cancer after the diagnosis (95\%) using HAM scale.

We found that the majority has major anxiety (61\%) and $34 \%$ has minor anxiety.

Our results are similar to those of Lichtenthal, who assessed the need of parents of children with cancer for mental health support and reported that $85 \%$ of parents had high anxiety scores [27].

Table 6. Prevalence of depression in parents of children with cancer in the literature.

\begin{tabular}{ccccc}
\hline Authors & Country & year & Size of sample & Prevalence of depression \\
\hline Our trial & Tunisia & 2021 & 43 & $86 \%$ \\
Battcharya K [23] & India & 2016 & 58 & $78.3 \%$ \\
AL-Maliki SK [22] & Iraq & 2016 & 336 & $70.5 \%$ \\
Rodriguez EM [26] & USA & 2016 & 100 & $38 \%$ \\
K. Dietrich [24] & Allemagne & 2016 & 213 & $42 \%$ \\
Kostak MA [25] & Turquie & 2013 & 44 & $36 \%$ \\
\hline
\end{tabular}


Table 7. Prevalence of anxiety in the parents of child with cancer in the literature.

\begin{tabular}{ccccc}
\hline The authors & country & year & size of sample & Prevalence of anxiety \\
\hline Our trial & Tunisia & 2021 & 43 & $95 \%$ \\
Lichtenhal [27] & Australia & 2015 & 120 & $85 \%$ \\
Boman [28] & Suéde & 2003 & 264 & $66 \%$ \\
Duetrich [24] & Allemagne & $2016(1$ year $)$ & 213 & $54 \%$ \\
Dunn [20] & USA & 2013 & 286 & $37 \%$ \\
Dahliquist [34] & USA & 1993 & 226 & $13 \%$ \\
\hline
\end{tabular}

Moreover Boman $\mathrm{K}$ found high levels of anxiety in two thirds of the parents [28]. Similarly, Dietrich K found $54 \%$ of the parents have the diagnostic of anxiety [24].

These findings differ from those observed by Dunn et al., Dahlquist LM where only $37 \%$ and $13 \%$ respectively of parents have scores in favor of anxiety.

Anxiety is variable over time; it most often occurs at the time of diagnosis and decreases over time. Parents of children newly diagnosed or in active therapy report more anxiety symptoms than parents of children not in treatment, in remission, or in relapse [29] [30] [31].

Parents of relapsed children show higher levels of anxiety than parents of survivors or dead children [32].

Most anxiety reactions in parents occur at the time of diagnosis, with predominance in mothers. It can persist even up to five years or more after diagnosis [33].

Table 7 illustrates the prevalence of anxiety in our trial in comparison with the findings in the literature.

In our study, among the socio-demographic factors, female sex of parents was correlated with a significant risk of stress and anxiety with a $\mathrm{p}<0.05$.

Our sample of mothers was large enough this is because we have found a significant correlation.

Our findings are similar to several trials reporting an increased risk of psychological distress in mothers [35].

Our study has certain limitations. One of these limitations is the number of fathers which is significantly underrepresented.

\section{Conclusions}

The diagnosis of pediatric cancer is a potentially traumatic event and a major source of psychological distress for parents.

The objective of our study was to evaluate the psychological distress in parents of children with cancer. Our results showed a high prevalence of anxiety and depressive disorders among parents of children diagnosed with cancer and a significant correlation between stress and anxiety with the female sex of parents.

Our results were similar to several studies although other risk factors for psy- 
chological distress in parents of children with cancer have been described in the literature.

These results suggest also that psychosocial support should be offered to parents of children diagnosed with cancer in order to optimize cancer management.

\section{Conflicts of Interest}

The authors declare no conflicts of interest regarding the publication of this paper.

\section{References}

[1] Kellie, S.J. and Howard, S.C. (2008) Global Child Health Priorities: What Role for Paediatric Oncologists? European Journal of Cancer, 44, 2388-2396.

https://doi.org/10.1016/j.ejca.2008.07.022

[2] Valery, P.C., Moore, S.P., Meiklejohn, J. and Bray, F. (2014) International Variations in Childhood Cancer in Indigenous Populations: A Systematic Review. The Lancet Oncology, 15, e90-e103. https://doi.org/10.1016/S1470-2045(13)70553-9

[3] Long, K.A. and Marsland, A.L. (2011) Family Adjustment to Childhood Cancer: A Systematic Review. Clinical Child and Family Psychology Review, 14, 57-88. https://doi.org/10.1007/s10567-010-0082-Z

[4] Lindahl Norberg, A. (2004) Stress and Coping in Parents of Children with Cancer. Karolinska Universitetssjukhuset, Stockholm.

[5] Weiss, D.S. (2007) The Impact of Event Scale: Revised. In: Wilson, J.P. and Tang, C.S., Eds., Cross-Cultural Assessment of Psychological Trauma and PTSD, Springer, Boston, 219-238. https://doi.org/10.1007/978-0-387-70990-1_10

[6] Bech, P., Allerup, P., Maier, W., Albus, M., Lavori, P. and Ayuso, J.L. (1992) The Hamilton Scales and the Hopkins Symptom Checklist (SCL-90). A Cross-National Validity Study in Patients with Panic Disorders. The British Journal of Psychiatry, 160, 206-211. https://doi.org/10.1192/bjp.160.2.206

[7] Warmerdam, J., Zabih, V., Kurdyak, P., Sutradhar, R., Nathan, P.C. and Gupta, S. (2019) Prevalence of Anxiety, Depression, and Posttraumatic Stress Disorder in Parents of Children with Cancer: A Meta-Analysis. Pediatric Blood \& Cancer, 66, Article ID: e27677. https://doi.org/10.1002/pbc.27677

[8] Republique Tunisienne Ministere de la Sante (2021) Plan pour la lutte contre le cancer 2015-2019.

https://www.iccp-portal.org/system/files/plans/Plan pour la lutte contre le cancer 2015-2019 Tunisie.pdf

[9] Gupta, S., Howard, S.C., Hunger, S.P., Antillon, F.G., Metzger, M.L., Israels, T., et al. (2015) Treating Childhood Cancer in Low- and Middle-Income Countries. In: Gelband, H., Jha, P., Sankaranarayanan, R., Horton, S., Eds., Cancer. Disease Control Priorities, Third Edition (Volume 3), The International Bank for Reconstruction and Development/The World Bank, Washington. http://www.ncbi.nlm.nih.gov/books/NBK343626/

[10] Jantien Vrijmoet-Wiersma, C.M., van Klink, J.M.M., Kolk, A.M., Koopman, H.M., Ball, L.M. and Maarten Egeler, R. (2008) Assessment of Parental Psychological Stress in Pediatric Cancer: A Review. Journal of Pediatric Psychology, 33, 694-706. https://doi.org/10.1093/jpepsy/jsn007

[11] Lewis, G. (1996) DSM-IV. Diagnostic and Statistical Manual of Mental Disorders, 
4th edn. By the American Psychiatric Association. (PP. 886; £34.95.) APA: Washington, DC.1994. Psychological Medicine, 26, 651-652.

https://doi.org/10.1017/S0033291700035765

[12] Kazak, A.E., Boeving, C.A., Alderfer, M.A., Hwang, W.-T. and Reilly, A. (2005) Posttraumatic Stress Symptoms during Treatment in Parents of Children with Cancer. Journal of Clinical Oncology, 23, 7405-7410.

https://doi.org/10.1200/JCO.2005.09.110

[13] Alderfer, M.A., Cnaan, A., Annunziato, R.A. and Kazak, A.E. (2005) Patterns of Posttraumatic Stress Symptoms in Parents of Childhood Cancer Survivors. Journal of the Division of Family Psychology of the American Psychological Association, 19, 430-440. https://doi.org/10.1037/0893-3200.19.3.430

[14] Gentes, E.L., et al. (2014) DSM-5 Posttraumatic Stress Disorder: Factor Structure and Rates of Diagnosis. Journal of Psychiatric Research, 59, 60-67. https://www.sciencedirect.com/science/article/abs/pii/S0022395614002507

[15] Iranmanesh, S., Shamsi, A. and Dehghan, M. (2015) Post-Traumatic Stress Symptoms among Iranian Parents of Children during Cancer Treatment. Issues in Mental Health Nursing, 36, 279-285. https://doi.org/10.3109/01612840.2014.983622

[16] Barakat, L.P., et al. (2005) Posttraumatic Growth in Adolescent Survivors of Cancer and Their Mothers and Fathers. Journal of Pediatric Psychology, 31, 413-419. https://pubmed.ncbi.nlm.nih.gov/16093518/

[17] McCarthy, M.C., Ashley, D.M., Lee, K.J. and Anderson, V.A. (2012) Predictors of Acute and Posttraumatic Stress Symptoms in Parents Following Their Child's Cancer Diagnosis. Journal of Traumatic Stress, 25, 558-566.

https://doi.org/10.1002/jts.21745

[18] Kassam-Adams N, Fleisher CL, Winston FK. (2009) Acute Stress Disorder and Posttraumatic Stress Disorder in Parents of Injured Children. Journal of Traumatic Stress, 22, 294-302. https://doi.org/10.1002/jts.20424

[19] Hedström, M., Haglund, K., Skolin, I. and von Essen, L. (2003) Distressing Events for Children and Adolescents with Cancer: Child, Parent, and Nurse Perceptions. Journal of Pediatric Oncology Nursing, 20, 120-132. https://doi.org/10.1053/jpon.2003.76

[20] Dunn, M.J., Rodriguez, E.M., Barnwell, A.S., Grossenbacher, J.C., Vannatta, K., Gerhardt, C.A., et al. (2012) Posttraumatic Stress Symptoms in Parents of Children with Cancer within Six Months of Diagnosis. Health Psychology, 31, 176-185. https://doi.org/10.1037/a0025545

[21] Taïeb, O., Moro, M.R., Baubet, T., Revah-Lévy, A. and Flament, M.F. (2003) Posttraumatic Stress Symptoms after Childhood Cancer. European Child \& Adolescent Psychiatry, 12, 255-264. https://doi.org/10.1007/s00787-003-0352-0

[22] Al-Maliki, S.K., Al-Asadi, J., Al-Waely, A. and Agha, S. (2016) Prevalence and Levels of Depression among Parents of Children with Cancer in Basrah, Iraq. Sultan Qaboos University Medical Journal, 16, e329-e334. https://doi.org/10.18295/squmj.2016.16.03.011

[23] Rahmani, A., Azadi, A., Pakpour, V., Faghani, S. and Afsari, E.A. (2018) Anxiety and Depression: A Cross-Sectional Survey among Parents of Children with Cancer. Indian Journal of Palliative Care, 24, 82-85.

[24] Dietrich, K., Leiss, U., Griessmeier, B., Wiener, A., Minetzke-Gruner, A.-C., Linhart, D., et al. (2016) Parental Distress Caused by Child's Cancer Diagnosis. Klinische Pädiatrie, 228, 149-156. https://doi.org/10.1055/s-0042-101345

[25] Kostak, M.A. and Avci, G. (2013) Hopelessness and Depression Levels of Parents of 
Children with Cancer. Asian Pacific Journal of Cancer Prevention, 14, 6833-6838. https://doi.org/10.7314/APJCP.2013.14.11.6833

[26] Rodriguez, E.M., Murphy, L., Vannatta, K., Gerhardt, C.A., Young-Saleme, T., Saylor, M., et al. (2016) Maternal Coping and Depressive Symptoms as Predictors of Mother-Child Communication about a Child's Cancer. Journal of Pediatric Psychology, 41, 329-339. https://doi.org/10.1093/jpepsy/jsv106

[27] Lichtenthal, W.G., Corner, G.W., Sweeney, C.R., Wiener, L., Roberts, K.E., Baser, R.E., et al. (2015) Mental Health Services for Parents Who Lost a Child to Cancer: If We Build Them, Will They Come? Journal of Clinical Oncology, 33, 2246-2253. https://doi.org/10.1200/JCO.2014.59.0406

[28] Boman, K., Lindahl, A. and Björk, O. (2003) Disease-Related Distress in Parents of Children with Cancer at Various Stages after the Time of Diagnosis. Acta oncologica (Stockholm, Sweden), 42, 137-146. https://doi.org/10.1080/02841860310004995

[29] Santacroce, S. (2002) Uncertainty, Anxiety, and Symptoms of Posttraumatic Stress in Parents of Children Recently Diagnosed with Cancer. Journal of Pediatric Oncology Nursing, 19, 104-111. https://doi.org/10.1177/104345420201900305

[30] Brown, K.A. and Barbarin, O.A. (1996) Gender Differences in Parenting a Child with Cancer. Social Work in Health Care, 22, 53-71. https://doi.org/10.1300/J010v22n04_04

[31] Heiney, S.P. (1997) Impact of Parental Anxiety on Child Emotional Adjustment When a Parent Has Cancer. Oncology Nursing Forum, 24, 655-661. https://europepmc.org/article/med/9159781

[32] Wijnberg-Williams, B.J., Kamps, W.A., Klip, E.C. and Hoekstra-Weebers, J.E.H.M. (2006) Psychological Adjustment of Parents of Pediatric Cancer Patients Revisited: Five Years Later. Psychooncology, 15, 1-8. https://doi.org/10.1002/pon.927

[33] Bayat, M., Erdem, E. and Gül Kuzucu, E. (2008) Depression, Anxiety, Hopelessness, and Social Support Levels of the Parents of Children with Cancer. Journal of Pediatric Oncology Nursing, 25, 247-253. https://doi.org/10.1177/1043454208321139

[34] Dahlquist, L.M., Czyzewski, D.I., Copeland, K.G., Jones, C.L., Taub, E. and Vaughan, J.K. (1993) Parents of Children Newly Diagnosed with Cancer: Anxiety, Coping, and Marital Distress. Journal of Pediatric Psychology, 18, 365-376. https://doi.org/10.1093/jpepsy/18.3.365

[35] von Essen, L., et al. (2004) Swedish Mothers and Fathers of a Child Diagnosed with Cancer a Look at Their Quality of Life. Acta Oncologica, 43, 474-479.

https://www.tandfonline.com/doi/abs/10.1080/02841860410029348 


\section{Appendix}

\section{Appendix 1. Impact of Events-Scale-Revised}

\section{IMPACT OF EVENTS SCALE-Revised (IES-R)}

INSTRUCTIONS: Below is a list of difficulties people sometimes have after stressful life events. Please read each item, and then indicate how distressing each difficulty has been for you DURING THE PAST SEVEN DAYS with respect to

that occurred on

distressed or bothered by these difficulties?

(date). How much have you been

(event)

\begin{tabular}{|l|c|c|c|c|c|}
\hline & Not at all & A little bit & Moderately & Quite a bit & Extremely \\
\hline $\begin{array}{l}\text { 1. Any reminder brought back feelings } \\
\text { about it }\end{array}$ & 0 & 1 & 2 & 3 & 4 \\
\hline 2. I had trouble staying asleep & 0 & 1 & 2 & 3 & 4 \\
\hline $\begin{array}{l}\text { 3. Other things kept making me think } \\
\text { about it. }\end{array}$ & 0 & 1 & 2 & 3 & 4 \\
\hline 4. I felt irritable and angry & 0 & 1 & 2 & 3 & 4 \\
\hline $\begin{array}{l}\text { 5. I avoided letting myself get upset when } \\
\text { I thought about it or was reminded of it }\end{array}$ & 0 & 1 & 2 & 3 & 4 \\
\hline $\begin{array}{l}\text { 6. I thought about it when I didn't mean } \\
\text { to }\end{array}$ & 0 & 1 & 2 & 3 & 4 \\
\hline $\begin{array}{l}\text { 7. I felt as if it hadn't happened or wasn't } \\
\text { real. }\end{array}$ & 0 & 1 & 2 & 3 & 4 \\
\hline 8. I stayed away from reminders of it. & 0 & 1 & 2 & 3 & 4 \\
\hline 9. Pictures about it popped into my mind. & 0 & 1 & 2 & 3 & 4 \\
\hline 10. I was jumpy and easily startled. & 0 & 1 & 2 & 3 & 4 \\
\hline 11. I tried not to think about it. & 0 & 1 & 2 & 3 & 4 \\
\hline $\begin{array}{l}\text { 12. I was aware that I still had a lot of } \\
\text { feelings about it, but I didn't deal with } \\
\text { them. }\end{array}$ & 0 & 1 & 2 & 3 & 4 \\
\hline $\begin{array}{l}\text { 13. My feelings about it were kind of } \\
\text { numb. }\end{array}$ & 0 & 1 & 2 & 3 & 4 \\
\hline $\begin{array}{l}\text { 14. I found myself acting or feeling like I } \\
\text { was back at that time. }\end{array}$ & 0 & 1 & 2 & 3 & 4 \\
\hline 15. I had trouble falling asleep. & 0 & 1 & 2 & 3 & 4 \\
\hline $\begin{array}{l}\text { 16. I had waves of strong feelings about } \\
\text { it. }\end{array}$ & 0 & 1 & 2 & 3 & 4 \\
\hline 17. I tried to remove it from my memory. & 0 & 1 & 2 & 3 & 4 \\
\hline 18. I had trouble concentrating. & 0 & 1 & 2 & 3 & 4 \\
\hline $\begin{array}{l}\text { 19. Reminders of it caused me to have } \\
\text { physical reactions, such as sweating, } \\
\text { trouble breathing, nausea, or a pounding } \\
\text { heart. }\end{array}$ & 0 & 1 & 2 & 3 & 4 \\
\hline 20. I had dreams about it. & 0 & 1 & 2 & 3 & 4 \\
\hline 21. I felt watchful and on-guard. & 0 & 1 & 2 & 3 & 4 \\
\hline 22. I tried not to talk about it. & 0 & 1 & 2 & 3 & 4 \\
\hline
\end{tabular}

Total IES-R Score:

INT: $1,2,3,6,9,14,16,20$

AVD: $5,7,8,11,12,13,17,22$

HYP: $4,10,15,18,19,21$

Weiss, D.S. (2007). The Impact of Event Scale-Revised. In J.P. Wilson, \& T.M. Keane (Eds.)

Assessing psychological trauma and PTSD: a practitioner's handbook ( $2^{\text {nd }} \mathrm{ed.}$. pp. 168-189). New York: Guilford Press.

AETR2N

22

$1 / 13 / 2012$ 


\section{Revised Impact of Event Scale (22 questions):}

The revised version of the Impact of Event Scale (IES-r) has seven additional questions and a scoring range of 0 to 88 .

On this test, scores that exceed 24 can be quite meaningful. High scores have the following associations.

\section{Score (IES-r) Consequence}

\begin{tabular}{|c|l|}
\hline 24 or more & $\begin{array}{l}\text { PTSD is a clinical concern. } \\
\text { who do not have full PTSD will have partial PTSD or at } \\
\text { least some of the symptoms. }\end{array}$ \\
\hline $\begin{array}{c}33 \text { and } \\
\text { above }\end{array}$ & $\begin{array}{l}\text { This represents the best cutoff for a probable diagnosis } \\
\text { of PTSD. }\end{array}$ \\
\hline 37 or more & $\begin{array}{l}\text { This is high enough to suppress your immune } \\
\text { system's functioning (even } 10 \text { years after an impact } \\
\text { event). }{ }^{8}\end{array}$ \\
\hline
\end{tabular}

The IES-R is very helpful in measuring the affect of routine life stress, everyday traumas and acute stress

\section{References:}

1. Horowitz, M. Wilner, N. \& Alvarez, W. (1979). Impact of Event Scale: A measure of subjective stress. Psychosomatic Medicine, 41, 209-218.

2. Weiss, D.S., \& Marmar, C.R. (1997). The Impact of Event Scale-Revised. In J.P. Wilson \& T.M. Keane (Eds.), Assessing Psychological Trauma and PTSD (pp.399-411). New York: Guilford.

3. Hutchins, E. \& Devilly, G.J. (2005). Impact of Events Scale. Victim's Web Site. http://www.swin.edu.au/victims/resources/assessment/ptsd/ies.html

4. Coffey, S.F. \& Berglind, G. (2006). Screening for PTSD in motor vehicle accident survivors using PSS-SR and IES. Journal of Traumatic Stress. 19 (1): 119-128.

5. Neal, L.A., Walter, B., Rollins, J., et al. (1994). Convergent Validity of Measures of PostTraumatic Stress Disorder in a Mixed Military and Civilian Population. Journal of Traumatic Stress. 7 (3): 447-455.

6. Asukai, N. Kato, H. et al. (2002). Reliability and validity of the Japanese-language version of the Impact of event scale-revised (IES-R-J). Journal of Nervous and Mental Disease. 190 (3): 175182.

7. Creamer, M. Bell, R. \& Falilla, S. (2002). Psychometric properties of the Impact of Event ScaleRevised. Behaviour Research and Therapy. 41: 1489-1496.

8. Kawamura, N. Yoshiharu, K. \& Nozomu, A. (2001) Suppression of Cellular Immunity in Men with a Past History of Post Traumatic Stress Disorder. American Journal of Psychiatry. 158: 484486 


\section{Hamilton Anxiety Rating Scale (HAM-A)}

\section{Reference: Hamilton M.The assessment of anxiety states by rating. Br J Med Psychol I959;} 32:50-55.

Rating Clinician-rated

Administration time 10-15 minutes

Main purpose To assess the severity of symptoms of anxiety

Population Adults, adolescents and children

\section{Commentary}

The HAM-A was one of the first rating scales developed to measure the severity of anxiety symptoms, and is still widely used today in both clinical and research settings. The scale consists of 14 items, each defined by a series of symptoms, and measures both psychic anxiety (mental agitation and psychological distress) and somatic anxiety (physical complaints related to anxiety). Although the HAM-A remains widely used as an outcome measure in clinical trials, it has been criticized for its sometimes poor ability to discriminate between anxiolytic and antidepressant effects, and somatic anxiety versus somatic side effects. The HAM-A does not provide any standardized probe questions. Despite this, the reported levels of interrater reliability for the scale appear to be acceptable.

\section{Scoring}

Each item is scored on a scale of 0 (not present) to 4 (severe), with a total score range of $0-56$, where $<17$ indicates mild severity, 18-24 mild to moderate severity and 25-30 moderate to severe.

\section{Versions}

The scale has been translated into: Cantonese for China, French and Spanish. An IVR version of the scale is available from Healthcare Technology Systems.

\section{Additional references}

Maier W, Buller R, Philipp M, Heuser I. The Hamilton Anxiety Scale: reliability, validity and sensitivity to change in anxiety and depressive disorders. J Affect Disord 1988; I4(I):6I-8.

Borkovec T and Costello E. Efficacy of applied relaxation and cognitive behavioral therapy in the treatment of generalized anxiety disorder. J Clin Consult Psychol 1993; 6I(4):6II-19

\section{Address for correspondence}

The HAM-A is in the public domain. 


\section{Hamilton Anxiety Rating Scale (HAM-A)}

Below is a list of phrases that describe certain feeling that people have. Rate the patients by finding the answer which best describes the extent to which he/she has these conditions. Select one of the five responses for each of the fourteen questions.
$0=$ Not present,
$\mathrm{I}=$ Mild,
2 = Moderate,
$3=$ Severe,
$4=$ Very severe

\section{Anxious mood}

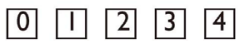

Worries, anticipation of the worst, fearful anticipation, irritability.

\section{Tension}

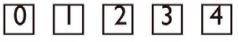

Feelings of tension, fatigability, startle response, moved to tears easily, trembling, feelings of restlessness, inability to relax.

3 Fears

$0 \longdiv { 2 } 3 4$

Of dark, of strangers, of being left alone, of animals, of traffic, of crowds.

\section{$4 \quad$ Insomnia}

\begin{tabular}{llll}
\hline 0 & 2 & 3 & 4
\end{tabular}

Difficulty in falling asleep, broken sleep, unsatisfying sleep and fatigue on waking, dreams, nightmares, night terrors.
5 Intellectual

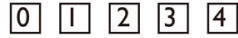

Difficulty in concentration, poor memory.
6 Depressed mood
011234

Loss of interest, lack of pleasure in hobbies, depression, early waking, diurnal swing.

\section{Somatic (muscular) \\ 0,12234}

Pains and aches, twitching, stiffness, myoclonic jerks, grinding of teeth, unsteady voice, increased muscular tone.

\section{Somatic (sensory)

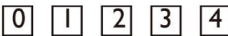

Tinnitus, blurring of vision, hot and cold flushes, feelings of weakness, pricking sensation.

\section{$\begin{array}{lllllllll}9 & \text { Cardiovascular symptoms } & 0 & 1 & 2 & 3 & 4\end{array}$}

Tachycardia, palpitations, pain in chest, throbbing of vessels, fainting feelings, missing beat.

\section{$\begin{array}{lllllll}10 & \text { Respiratory symptoms } & 0 & 1 & 2 & 3 & 4\end{array}$}

Pressure or constriction in chest, choking feelings, sighing, dyspnea.

\section{$\begin{array}{llllllll} & \text { II Gastrointestinal symptoms } & 0 & 0 & 0 & 3 & 4\end{array}$}

Difficulty in swallowing, wind abdominal pain, burning sensations, abdominal fullness, nausea, vomiting, borborygmi, looseness of bowels, loss of weight, constipation.

\section{Genitourinary symptoms 0}

Frequency of micturition, urgency of micturition, amenorrhea, menorrhagia, development of frigidity, premature ejaculation, loss of libido, impotence.

\section{$\begin{array}{lllllll}13 & \text { Autonomic symptoms } & 0 & 1 & 2 & 3 & 4\end{array}$}

Dry mouth, flushing, pallor, tendency to sweat, giddiness, tension headache, raising of hair.

\section{I4 Behavior at interview \\ \begin{tabular}{lll}
\hline 0 & $3 \quad 4$
\end{tabular}}

Fidgeting, restlessness or pacing, tremor of hands, furrowed brow, strained face, sighing or rapid respiration, facial pallor, swallowing, etc. 


\section{Appendix 3. The Beck's Depression Inventory (BDI)}

\section{Beck's Depression Inventory}

This depression inventory can be self-scored. The scoring scale is at the end of the questionnaire.

1 .

$0 \quad$ I do not feel sad.

1 I feel sad

2 I am sad all the time and I can't snap out of it.

3 I am so sad and unhappy that I can't stand it.

2.

$0 \quad$ I am not particularly discouraged about the future.

1 I feel discouraged about the future.

2 I feel I have nothing to look forward to.

3 I feel the future is hopeless and that things cannot improve.

3.

$0 \quad$ I do not feel like a failure.

1 I feel I have failed more than the average person.

2 As I look back on my life, all I can see is a lot of failures.

3 I feel I am a complete failure as a person.

4.

$0 \quad$ I get as much satisfaction out of things as I used to.

1 I don't enjoy things the way I used to.

2 I don't get real satisfaction out of anything anymore.

3 I am dissatisfied or bored with everything.

5.

6.

$0 \quad$ I don't feel particularly guilty

1 I feel guilty a good part of the time.

2 I feel quite guilty most of the time.

3 I feel guilty all of the time.

0 I don't feel I am being punished.

$1 \quad$ I feel I may be punished.

2 I expect to be punished.

3 I feel I am being punished.

7.

I don't feel disappointed in myself.

I am disappointed in myself.

I am disgusted with myself.

I hate myself.

8.

I don't feel I am any worse than anybody else.

1 I am critical of myself for my weaknesses or mistakes.

2 I blame myself all the time for my faults.

3 I blame myself for everything bad that happens.

9.

I don't have any thoughts of killing myself.

I have thoughts of killing myself, but I would not carry them out.

I would like to kill myself.

I would kill myself if I had the chance.

10.

I don't cry any more than usual.

I cry more now than I used to.

I cry all the time now.

2

I used to be able to cry, but now I can't cry even though I want to. 
11.

$0 \quad$ I am no more irritated by things than I ever was.

1 I am slightly more irritated now than usual.

2 I am quite annoyed or irritated a good deal of the time.

3 I feel irritated all the time.

12.

$0 \quad$ I have not lost interest in other people.

1 I am less interested in other people than I used to be.

2 I have lost most of my interest in other people.

3 I have lost all of my interest in other people.

13.

$0 \quad$ I make decisions about as well as I ever could.

1 I put off making decisions more than I used to.

2 I have greater difficulty in making decisions more than I used to.

3 I can't make decisions at all anymore.

14.

$0 \quad$ I don't feel that I look any worse than I used to.

1 I am worried that I am looking old or unattractive.

2 I feel there are permanent changes in my appearance that make me look unattractive

3 I believe that I look ugly.

15.

$0 \quad$ I can work about as well as before.

$1 \quad$ It takes an extra effort to get started at doing something.

$2 \quad$ I have to push myself very hard to do anything.

3 I can't do any work at all.

16.

$0 \quad$ I can sleep as well as usual.

$1 \quad$ I don't sleep as well as I used to.

2 I wake up 1-2 hours earlier than usual and find it hard to get back to sleep.

3 I wake up several hours earlier than I used to and cannot get back to sleep.

17.

$0 \quad$ I don't get more tired than usual.

$1 \quad$ I get tired more easily than I used to.

$2 \quad$ I get tired from doing almost anything.

$3 \quad$ I am too tired to do anything.

18.

$0 \quad$ My appetite is no worse than usual.

1 My appetite is not as good as it used to be.

2 My appetite is much worse now.

3 I have no appetite at all anymore.

19.

0 I haven't lost much weight, if any, lately.

1 I have lost more than five pounds.

2 I have lost more than ten pounds.

3 I have lost more than fifteen pounds. 
20.

$0 \quad$ I am no more worried about my health than usual.

1 I am worried about physical problems like aches, pains, upset stomach, or constipation.

2 I am very worried about physical problems and it's hard to think of much else.

3 I am so worried about my physical problems that I cannot think of anything else.

21.

$0 \quad$ I have not noticed any recent change in my interest in sex.

1 I am less interested in sex than I used to be.

2 I have almost no interest in sex.

3 I have lost interest in sex completely.

\section{INTERPRETING THE BECK DEPRESSION INVENTORY}

Now that you have completed the questionnaire, add up the score for each of the twenty-one questions by counting the number to the right of each question you marked. The highest possible total for the whole test would be sixty-three. This would mean you circled number three on all twenty-one questions. Since the lowest possible score for each question is zero, the lowest possible score for the test would be zero. This would mean you circles zero on each question. You can evaluate your depression according to the Table below.

Total Score Levels of Depression

$\begin{array}{ll}1-10 & \text { These ups and downs are considered normal } \\ 11-16 & \text { Mild mood disturbance } \\ 17-20 & \text { Borderline clinical depression } \\ 21-30 & \text { Moderate depression } \\ 31-40 & \text { Severe depression } \\ \text { over } 40 & \text { Extreme depression }\end{array}$

